\title{
Europe puts the squeeze on space projects
}

\section{Sally Goodman}

Europe's space scientists are facing some tough decisions, after the member states of the European Space Agency (ESA) agreed a five-year budget that will require some planned missions to be cut.

Meeting in Edinburgh last week, ministers from 15 European nations and Canada agreed funding for ESA's entire range of projects. They committed 1.869 billion euros (US\$1.6 billion) over five years to the agency's science programme, into which all members pay a mandatory subscription according to their wealth. This maintains roughly level funding, including a modest compensation for inflation. But David Southwood, director of ESA's science programme, had asked for 1.945 billion euros. "The outcome is satisfactory, but a big loss on what we were hoping for," he says.

Southwood speculates that a single big project is most likely to be sacrificed. He says the GAIA satellite, which would map the distances and positions of the billion brightest objects in the sky and is scheduled for launch by 2012, "is in some jeopardy". Lennart Lindegren of the Lund Observatory in Sweden, one of GAIA's principal investigators, says this would be "extremely disappointing".

Preparation for the Aurora programme, an ambitious long-term plan for robotic and human exploration of the Solar System (see Nature 411, 625; 2001), was one of the nonmandatory programmes given the go-ahead, but in reduced form. Delegates were shocked when Italy, which had been Aurora's main

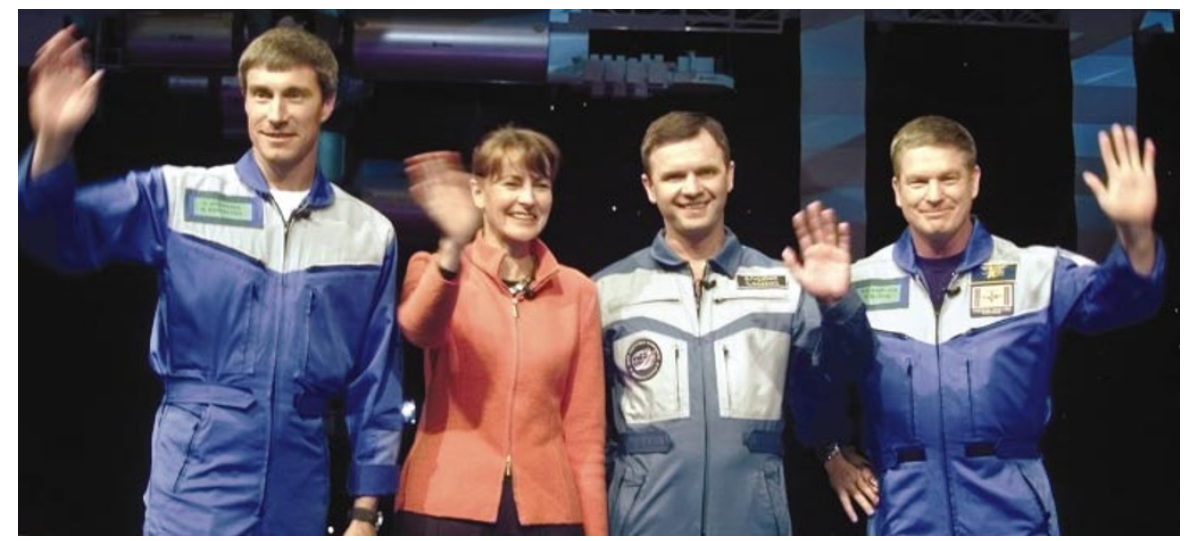

Goodbye? Edelgard Bulmahn with ISS crew (from left) Sergei Krikalev, Yuri Gidzenko, Bill Shepherd.

advocate, came to the table empty-handed.

Italy had originally offered to pay $40 \%$ of the 40 million euros needed for a three-year preparation programme. But given the current squeeze on research spending (see page 384), "Italy must be content to be one of the participants in a very reduced global programme", says Giovanni Bignami, scientific director of the Italian space agency. Under pressure from other ESA members, the Italian delegation finally agreed to contribute 2 million euros towards a total of 14 million euros. France, Britain, Spain, Belgium, Switzerland, Austria, Portugal and Canada also subscribed to the programme.

In a strong message to the United States, the ministers decided to hold back $60 \%$ of ESA's exploitation budget for the International Space Station (ISS), pending NASA's agreement to fulfil its original agreement to operate the ISS with a full crew of six. Without this, it will be hard to carry out scientific research. "Europe will fulfil its obligations and expects the same from our partners," said German science minister Edelgard Bulmahn, who chaired the meeting.

But given the nomination of a NASA administrator who appears determined to cap the space station's budget (see below), it is unclear whether ESA's move will have the desired effect. And there were signs that ESA members have doubts about the station's scientific potential. The ELIPS programme, which will support experiments in both physical and life sciences on board the ISS, received only 166.5 million euros of the requested budget of 320 million euros. www.esa.int

\section{Budgets come first as Bush chooses NASA head}

\section{Mark Schrope}

President George W. Bush has sent NASA a message about costs by nominating a budget expert with no aerospace or scientific background as the agency's administrator.
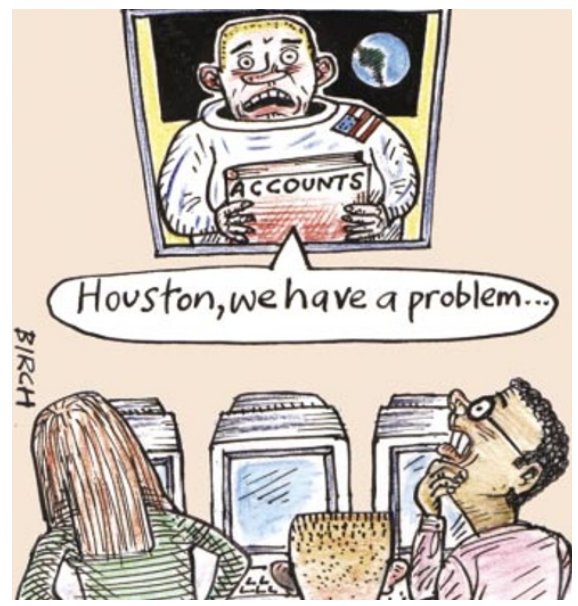

The nominee, Sean O'Keefe, a former secretary of the Navy and chief financial officer with the Department of Defense, was appointed as deputy director at the Office of Management and Budget in March. There he scrutinized overspending in the International Space Station programme, which he termed a "management and financial crisis".

If his appointment is confirmed, as expected, by the Senate, O'Keefe will have to implement reforms he recommended in his previous position, making working within budgets as important as technical excellence.

John Pike, a former head of space policy with the Federation of American Scientists, says that the Bush administration's policy is centred on the need to control the space station's budget. "The space programme has not been a priority for them," he says. "It was on the backburner before September and it isn't even on the stove now."

"It's an interesting choice," observes John
Logsdon, director of the Space Policy Institute at George Washington University in Washington, DC. “They are taking someone out of the centre of the Bush administration and sending him over to NASA to fix some perceived problems."

Scientists are not sure what to make of the nomination. "I was quite startled to begin with,” says Anneila Sargent of the California Institute of Technology in Pasadena, president of the American Astronomical Society. "But on reflection I have come to see that it might have very positive aspects." Because space science has traditionally managed its finances well, she says, it may find favour with a budget-conscious chief.

But Sargent is concerned that budget issues could override scientific and technological arguments altogether. "I think there has to be a balance," she says. "We can't do everything we want, but we can't be told that we can't do anything." 